\title{
Breve estudo sobre os usos dos termos empréstimo e estrangeirismo na tradição linguística em língua portuguesa
}

\author{
Brève étude sur l'usage des termes " empréstimo » et " estrangeirismo » dans la tradition linguistique en \\ langue portugaise \\ Mariana Giacomini Botta
}

Centro Universitário Ritter dos Reis - UniRitter - Porto Alegre - Rio Grande do Sul - Brasil

\begin{abstract}
Resumo: Na literatura linguística tradicional em língua portuguesa, em capítulos e obras dedicados à Lexicologia, encontram-se diferentes usos e definições para os termos empréstimo e estrangeirismo. Tais conceitos estão relacionados ao processo neológico pelo qual uma unidade lexical de um sistema linguístico passa a fazer a parte do léxico de outra língua, de maneira provisória ou definitiva. Esse fenômeno de ampliação lexical é, segundo Alves (2002), chamado de neologia por empréstimo. Imprecisões terminológicas aparecem com o uso de estrangeirismo: para a maioria dos pesquisadores, é o ponto de partida do processo, mas há estudiosos que consideram estrangeirismo não só a primeira etapa, como o processo e seu resultado, caracterizando-o como sinônimo de empréstimo. Existe também quem argumente que, enquanto o elemento for sentido como estrangeiro, será tido como estrangeirismo. Com base em teorias e pesquisas de autores como Guilbert (1973), Biderman (2001), Alves (2002), Carvalho (2010), Pruvost e Sablayrolles (2012), realiza-se um estudo léxico-semântico dos usos dos termos empréstimo e estrangeirismo em obras de referência da Linguística, publicadas em português. Os resultados mostram que, na constituição da terminologia da área, filólogos e gramáticos empregavam prioritariamente o termo empréstimo. Com o fortalecimento da Lexicologia e com o aumento do interesse pela neologia por empréstimo, ocorreu a popularização desse termo que, polissêmico, passou a concorrer com estrangeirismo. Acredita-se que contribuem para a imprecisão terminológica a questão ideológica envolvendo o emprego de estrangeirismo e a influência de obras internacionais, que implica em sucessivos processos de tradução não especializada.
\end{abstract}

Palavras-chave: Neologia, Empréstimo, Estrangeirismo, Terminologia Linguística.

Résumé: Dans la littérature linguistique traditionnelle en portugais, dans les chapitres et ouvrages consacrés à la Lexicologie, il existe différents usages et définitions pour les termes «empréstimo » (emprunt) et «estrangeirismo » (xenisme). Ces deux concepts sont liés au processus néologique par lequel une unité lexicale d'un système linguistique passe à intégrer le lexique d'une autre langue, à titre provisoire ou définitif. Ce phénomène d'élargissement lexical est appelé, selon Alves (2002), néologie par emprunt. Des inexactitudes terminologiques apparaissent lorsque le terme " estrangeirismo » est employé: pour la plupart des chercheurs, il s'agit du point de départ du processus, mais certains d'entre eux considèrent qu'il est non seulement la première étape, mais aussi le processus et son résultat, une sorte de synonyme de " empréstimo ». Il y a aussi ceux qui soutiennent que tant que l'élément est ressenti comme étranger, il sera considéré comme " estrangeirismo ». À partir de théories et de travaux de recherche d'auteurs tels que Guilbert (1973), Biderman (2001), Alves (2002), Carvalho (2010), Pruvost et Sablayrolles (2012), on propose une étude lexicosémantique de l'usage des termes «empréstimo » et «estrangeirismo » dans les ouvrages linguistiques de référence publiés en portugais. Les résultats montrent que, dans la constitution de la terminologie de ce domaine, des philologues et grammairiens ont préféré employer le terme «empréstimo ». Avec la croissance de la Lexicologie et l'agrandissement de l'intérêt par la néologie par emprunt, ce terme est devenu plus populaire et polysémique et il a commencé à concourir avec « estrangeirismo ». On pense que la question idéologique impliquant l'utilisation de « estrangeirismo » et l'influence d'œuvres internationales, impliquant des successifs processus de traduction non spécialisés, contribue à cette inexactitude terminologique.

Mots-clés: Neologie, Emprunt, Xenisme, Terminologie Linguistique. 


\section{Introdução}

Neste artigo, apresenta-se um estudo léxicosemântico preliminar dos usos dos termos empréstimo e estrangeirismo em obras de referência da Linguística, publicadas em língua portuguesa e preferencialmente escritas por autores brasileiros e portugueses dessa área. Parte-se da observação de que há, na literatura linguística tradicional em português, principalmente nos capítulos e obras dedicados à Lexicologia, uma grande variedade de empregos e definições dadas para esses termos, nem sempre com os mesmos sentidos ou referindo-se exatamente às mesmas noções.

Ambos os conceitos estão relacionados ao processo de ampliação lexical que, segundo Alves (2002 [1990]), é chamado de neologia por empréstimo, por meio do qual uma unidade de um sistema linguístico passa a fazer a parte do léxico de outra língua, de maneira provisória ou definitiva. Entretanto, parece não haver consenso entre os autores sobre as diferenças entre empréstimo e estrangeirismo: para alguns, os termos são sinônimos; para outros, são unidades com sentidos distintos e, reconhecendo a diferenciação, empregam um ou outro prioritariamente; e existe, ainda, quem prefira usar xenismo, para evitar o emprego da palavra estrangeirismo.

\begin{abstract}
"Para designar as palavras que passam do léxico de uma determinada língua para outra, têm sido utilizadas várias denominações. As mais comuns são: empréstimo, estrangeirismo e importação. Alguns autores chegam mesmo a usar estes termos de um modo diferenciado, aplicando-os de acordo com diferentes processos." (FREITAS; RAMILO; SOALHEIRO, 2003, s.p.)
\end{abstract}

Este estudo visa, portanto, a entender e tentar explicar essa imprecisão terminológica, verificar como e por que ela ocorre, a buscar quais fatores internos e externos podem tê-la motivado. Parte-se da hipótese de que a formação da terminologia dos estudos da neologia por empréstimo em língua portuguesa teve três momentos principais: um momento inicial, marcado pelo uso predominante do termo empréstimo, principalmente em obras de gramáticos e semanticistas, em que se observa uma maior influência de pesquisadores da Linguística francesa, como Saussure, Meillet e, principalmente, Guilbert e sua Teoria do Neologismo (1972); um momento intermediário, no qual se verifica a coexistência dos termos empréstimo e estrangeirismos, sendo usados praticamente como sinônimos, ou seja, um período de maior instabilidade; e o momento atual, em que ainda não há consenso, mas no qual os pesquisadores consideram a diferenciação, fazem a opção por um termo ou outro em suas pesquisas, na maioria das vezes sem discutir ou esclarecer esses conceitos, provavelmente devido à existência da citada diversidade de definições em circulação.

Para fundamentar esta investigação, foram consultados trabalhos de Guilbert (1972, 1973), Sablayrolles (2002, 2009), Humbley (2007), Pruvost e Sablayrolles (2012), além de Alves (1984, 1988, 2002 [1990], 2008), Barbosa (1979), Biderman (1984, 2001 [1978]) e Carvalho (1989, 2010), entre outros. Quanto à metodologia de análise, além da análise léxicosemântica estrutural - análise sêmica, de Pottier (1963), procede-se a um estudo das colocações, embasado em autores como Togeby (1965), Mel'čuk et al. (1984), Eluerd (2000), Moirand (2004) e Botta (2011). Na sequência, apresenta-se um panorama dos estudos da neologia, com ênfase no processo de empréstimo lexical.

\section{A neologia por empréstimo e os estrangeirismos}

Neologia é o nome dado a diferentes processos que têm como resultado a ampliação do acervo vocabular de uma língua. Esses processos podem ser de criação lexical, ampliação semântica ou de importação de unidades lexicais de outros sistemas linguísticos.

Produto da neologia, o neologismo pode ser, segundo Boulanger (1979), "uma unidade lexical de criação recente, uma nova acepção de uma palavra já existente, ou ainda, uma palavra recentemente emprestada de um sistema lingüístico estrangeiro e 
aceito numa língua" (BOULANGER, 1979, p. 65-66 apud ALVES, 1984b, p. 119).

Os neologismos definidos por esse autor podem ser gerados por dois tipos de processos neológicos, explicados por Alves (2001 [1990], p. 5): autóctone, decorrente da combinação ou modificação de elementos já existentes em um sistema linguístico, também chamado vernacular, e com base em estrangeirismo, aquele em que o acréscimo ao léxico se dá pela entrada de unidades lexicais de outros códigos, também chamado neologia por empréstimo ou por adoção.

Procedimento natural e universal de enriquecimento do acervo lexical das línguas, o empréstimo tem, segundo Pruvost e Sablayrolles (2012, p. 115), a característica de, ao mesmo tempo em que importa uma denominação, introduzir novas realidades, que podem ser concretas (como radar e fast food) ou abstratas (como vibe). Esses autores dizem que, apesar de haver a impressão de um uso crescente dos estrangeirismos que circulam na sociedade, principalmente anglicismos, eles ocupam apenas $2,5 \%$ do vocabulário dos dicionários e 0,6\% das palavras de um jornal diário de grande circulação, como mostram estudos realizados por pesquisadores franceses em 1980 e em 2000.

Os discursos alarmistas sobre o excesso de estrangeirismos nas línguas, portanto, não têm fundamentação científica. A maioria dos linguistas concorda que o empréstimo é um fenômeno linguístico tão natural quanto os outros processos de neologia. Guilbert (1973, p. 23) explica que se trata de um processo por meio do qual um signo, que funciona conforme as regras próprias do sistema linguístico de uma determinada língua, é inserido em outro sistema, que tem regras fonéticas, fonológicas, gráficas, morfológicas e sintáticas diferentes do primeiro, e a esse se adapta.

Além disso, esse autor distingue diversas formas de adaptações a que a unidade estrangeira está sujeita quando se integra à língua receptora: (1) alterações de ordem fonética e/ou gráfica; (2) modificações semânticas com manutenção da forma original; e (3) manutenção da significação original apesar da adaptação morfológica ao novo sistema. Para ele: "É o fenômeno de adaptação ao novo código que caracteriza o empréstimo, mais que a forma estrangeira." (GUILBERT, 1973, p. 23, tradução nossa).

As adaptações são imprevisíveis, o que indica que, conforme o grau de assimilação, as palavras podem ter status tanto de estrangeirismo como de empréstimo na língua receptora. Segundo Alves (1988), o termo estrangeirismo é mais utilizado para designar a palavra ou expressão sentidos como externos ao português. "O estrangeirismo que está se instalando é um verdadeiro neologismo e somente se tornará empréstimo quando não mais for sentido como estranho ao sistema da língua [...]." (ALVES, 1988, p. 3).

Para Sablayrolles (2009, p. 26-28), todos os neologismos apresentam uma escala de "neologicidade", eles podem ser mais ou menos neológicos de acordo com certos parâmetros. O período neológico seria também um parâmetro na escala, sendo o fator mais importante as flutuações do sentimento neológico do falante.

Além do sentimento de novidade por parte do falante nativo, que contribui para distinguir estrangeirismo e empréstimo, Alves (1984b) propõe outro critério: "Parece-nos, entretanto, que a freqüência do termo emprestado, ainda que empregado na sua forma nativa, constitui um critério para a sua aceitabilidade na língua portuguesa." (ALVES, 1984b, p. 125). Existem, ainda, os estrangeirismos que não se fixam na língua receptora, deixam de ser usados e nunca se tornam empréstimos.

Enquanto for sentida como externa à língua receptora, a unidade lexical estrangeira empregada em outro sistema linguístico está no que Alves (2002 [1990], p. 72) define como a primeira etapa da neologia por empréstimo. Por ainda não fazer parte do repertório lexical da nova língua, é chamada tecnicamente de estrangeirismo, e é usada com finalidades estilísticas.

Na segunda etapa, que a pesquisadora nomeia como tradução do estrangeirismo, a unidade 
importada vem acompanhada por uma tradução ou uma definição de seu significado, uma vez que o emissor supõe que "não poderá ser interpretado pelos receptores do texto" (ALVES, 2002 [1990], p. 76).

A terceira fase da integração do neologismo por empréstimo é aquela em que a palavra de outra língua pode manifestar algum tipo de adaptação gráfica, morfológica ou semântica. Guilbert (1975 apud ALVES, 1984b, p. 121) estabeleceu três critérios para identificar a passagem de uma unidade lexical importada por essa fase. São eles: morfossintático, semântico e fonológico.

O critério morfossintático trata de a palavra proveniente de outro sistema passar a ser base de derivação ou composição de novas formas na língua receptora, o que indica que ela está se anexando ao léxico da comunidade linguística. Observa-se também a criação de palavras com sufixos estrangeiros associados a bases vernáculas. Há, ainda, a tendência à conservação da classe gramatical que a unidade tinha na língua de origem, sendo mais comum que os substantivos sejam integrados no masculino. Pode ocorrer o chamado decalque, uma tradução literal da palavra, como arranha-céu (skyscraper). É o que Sablayrolles (2002) chama de calco morfológico.

O critério semântico indica que o elemento linguístico estrangeiro, introduzido na língua receptora com um único significado, ao se integrar ao novo sistema, torna-se polissêmico. Alves (1984b, p. 123) cita como exemplo a palavra em inglês jeans (peça de roupa - calça) que, em português, passou a significar o tipo de tecido de que a peça é feita.

O critério fonológico está relacionado com a adaptação sonora da unidade lexical ao sistema da língua receptora, que nem sempre corresponde a uma adaptação gráfica.

Aos poucos, quando passa a ser aceita pela comunidade de falantes e torna-se de uso frequente, a unidade lexical importada perde seu caráter de estrangeirismo - etapa final da integração do neologismo por empréstimo. Após a incorporação da unidade ao léxico do novo sistema, a permanência do empréstimo na língua dependerá de fatores sociais, culturais e comunicativos. De acordo com Biderman (2001), esse termo:

Será incorporado a um campo semântico e começará a sofrer influxos de seus vizinhos de significação. A combinação léxica no discurso e as conotações estilísticas também imprimirão a ele matizes novos, ampliando seu halo de significação. Passará, assim, a fazer parte da semântica evolutiva da língua. (BIDERMAN, 2001 [1978], p. 212).

A inclusão da palavra no sistema da língua importadora é efetivada, segundo Barbosa (1978, p. 205), com sua inserção em um dicionário, o que lhe confere o estatuto de elemento lexical dessa língua. Para Alves (1984b, p. 125), é o lexicógrafo quem tem o poder de decidir sobre a aceitabilidade de uma palavra e sua incorporação à língua.

Pelo que foi apresentado, a neologia por empréstimo parece ser um processo mais ou menos regular, ao menos nas línguas românicas. Apesar disso, como grande parte dos fenômenos linguísticos, ela se encontra em constante mudança / evolução. Atualmente, com as novas tecnologias da comunicação e da informação, o maior contato entre pessoas de línguas e culturas diferentes, e de maneira mais intensa e instantânea, observa-se o aparecimento de novas formas de empréstimo, que não são o foco desta pesquisa. Entretanto, para que se possa futuramente estudá-las de maneira adequada, é preciso que haja uma terminologia que dê conta dessa tarefa de modo satisfatório, sem ambiguidades, o que já não ocorre atualmente.

Sablayrolles, Jacquet-Pfau e Humbley (2011) afirmam que o termo empréstimo é problemático por diversos motivos. Em primeiro lugar, por ser usualmente empregado para tratar de fenômenos variados e desiguais. Em segundo lugar, por conta da necessidade de se distinguir empréstimos e criações sob influência, pelo risco de se cristalizar, sob uma mesma denominação, realidades diferentes.

Segundo esses autores, mesmo que todo empréstimo resulte da influência de uma "língua fonte" sobre uma "língua alvo", é preciso considerar que nem toda influência externa exercida por uma "língua fonte" sobre uma "língua alvo" vai, necessariamente, gerar um empréstimo. Entende-se, 
assim, que devem ser feitos estudos mais detalhados e precisos sobre os processos de ampliação do léxico, buscando diferenciar os fenômenos que envolvem a terminologia linguística sobre o tema.

\section{A análise léxico-semântica}

A Lexicologia é definida como a ciência que estuda o léxico e a sua organização. É uma disciplina que tem como principal objetivo a análise do léxico dos sistemas linguísticos e dos vocabulários. Segundo Biderman (2001 [1978]), suas principais funções são apresentar informações sobre as unidades lexicais necessárias ao uso e caracterizar a estrutura interna do léxico, tanto em relação ao conteúdo quanto à forma. Por isso, ela costuma ser dividida em duas disciplinas complementares: a Semântica lexical e a Morfologia lexical.

$\mathrm{Na}$ perspectiva Estruturalista, a Semântica lexical se ocupa prioritariamente da análise e da descrição do significado das unidades lexicais. $O$ método tradicional de trabalho parte da noção de valor apresentada por Saussure (1916), por meio da realização da análise sêmica ou componencial, que foi desenvolvida por Pottier, nos anos 1960. Ele é inspirado no modelo fonológico, baseado na comparação de unidades com alguma semelhança e, pelo menos, uma diferença. Trata-se da decomposição do significado da unidade lexical em traços de significação, os semas, método que permite verificar as relações de significação existentes entre as palavras pertencentes a um mesmo campo lexical.

Segundo Eluerd (2000 p. 30), a abordagem da lexicologia tradicional estuda o conteúdo das unidades lexicais em duas direções complementares: (a) das relações paradigmáticas que existem entre as unidades (sinonímia, antonímia, hiperonímia hiponímia e meronímia - holonímia); (b) das combinações sintagmáticas nas quais uma unidade pode entrar, as significações ou os empregos diferentes que essas combinações suscitam (como a homonímia e a polissemia).

Em relação aos sentidos que uma unidade lexical pode ter quando efetivamente utilizada em discurso, não se pode descartar a importância das combinações com outras unidades na cadeia sintagmática, como destaca Eluerd e já havia sido afirmado por Benveniste (1995, p. 290), para quem o sentido de uma unidade lexical é definido pela totalidade de seus empregos, sua distribuição, e pelos tipos de combinações que daí resultam. Para esse autor, há práticas e associações no ambiente léxico-sintático das unidades que parecem ser mais recorrentes que outras, e podem ser constituintes dos significados.

Togeby (1965, p. 4) também falou sobre o que hoje se conhece como colocação, ao afirmar que o comportamento sintático das unidades nos discursos pode revelar dados que compõem seus significados. Por isso, para ele, a descrição semântica deve considerar também as informações referentes ao comportamento sintático desses elementos linguísticos. Opinião semelhante tinha Lyons (1977): "há habitualmente em cada palavra um núcleo sólido de significado, relativamente estável, e que só dentro de certos limites pode ser modificado pelo contexto" (LYONS, 1977, p. 103).

Assim, entende-se que a análise sêmica precisa ser acompanhada de algum outro método que dê conta das colocações, as combinações que as unidades lexicais estabelecem de maneira mais ou menos frequente na cadeia sintagmática, pois elas também constituem seus significados.

Uma opção, na abordagem da Linguística Estrutural, é encontrada na Teoria Sentido-Texto, da Lexicologia Explicativa e Combinatória (MEL'ČUK et al., 1984). Uma alternativa seria adotar uma perspectiva discursiva, como a proposta em Botta (2011), inspirada no Modelo Dialógico da Enunciação, de Moirand (2004), alinhado à Análise do Discurso de linha francesa. As duas propostas consideram como constituintes do sentido lexical: (a) o comportamento sintático das unidades lexicais; (b) as informações semânticas fornecidas por ou compartilhadas com outros elementos do ambiente sintático em que a unidade lexical é empregada. 


\section{Procedimentos metodológicos}

Para a investigação dos usos dos termos estrangeirismo e empréstimo na tradição linguística em língua portuguesa, o primeiro passo foi a constituição de um corpus composto por textos de filólogos, gramáticos e pesquisadores brasileiros e portugueses das áreas de Lexicologia e Lexicografia sobre os temas neologia, empréstimos e/ou estrangeirismos, de diferentes épocas.

$\mathrm{Na}$ sequência, procedeu-se a um estudo das ocorrências dos termos empréstimo e estrangeirismo nesse corpus, considerando sua frequência, seu sentido e suas associações preferenciais na cadeira sintagmática (colocação). Até o momento, todos os procedimentos de análise têm sido realizados manualmente, sem 0 uso de softwares de processamento automático, o que se pretende adotar em fases futuras da pesquisa.

\subsection{Constituição do corpus}

O corpus desta pesquisa é composto por três tipos de obras:

(1) Livros e artigos dos principais pesquisadores brasileiros e portugueses de Lexicologia / Lexicografia que tratam de neologia - empréstimos / estrangeirismos, disponíveis para consulta on-line em bases de dados ou em qualquer outro tipo de acervo digital e para acesso físico, na cidade de Porto Alegre em 2019 (período e local da coleta);

(2) Livros e artigos de filólogos e gramáticos, de reconhecida contribuição aos estudos da língua portuguesa, que tenham abordado o tema dos neologismos por empréstimo / importação;

(3) Trabalhos acadêmicos de pesquisadores brasileiros e portugueses, dedicados aos estudos dos neologismos por empréstimo / importação, disponíveis on-line.

A escolha desses três tipos de documentos se justifica pelo fato de a proposta desta investigação ser tentar entender e explicar a imprecisão na terminologia Linguística em torno dos termos empréstimo e estrangeirismo, muitas vezes usados como sinônimos, e verificar como e por que ela ocorre, buscando os fatores internos e externos que podem tê-la motivado.

\section{Análises preliminares}

A primeira etapa das análises consiste na observação dos contextos de uso das palavras empréstimo e estrangeirismo em obras dos grupos 1 e 2 do corpus. Do grupo 2, "Livros e artigos de filólogos e gramáticos", destacam-se as seguintes ocorrências (todos os grifos são nossos):

(1) Para designar as contribuições adventícias com que se aumenta o léxico de um idioma, servem-se os linguistas de um termo de extraordinária polidez: "empréstimos", "emprunts" (francês), "loan-words" (inglês), "Lehnwörter" (alemão). (SAID ALI, 2008 [1908], p. 214)

(2) Com a expansão natural do vocabulário, [...] mal se concilia a doutrina que defende a pureza da linguagem. [...] Admite latinismos, admite grecismos, não se opõe talvez a hispanismos e italianismos, mas repele os galicismos com singular veemência. (SAID ALI, 2008 [1908], p. 215)

(3) [...] na língua viva do país, na expressão diária de todos nós, são muitos os empréstimos indígenas sem mencionarmos os nomes de lugares, da fauna, da flora, dos produtos caseiros, dos utensílios familiares. (SILVEIRA BUENO, 1967 [1959], p. 219)

(4) Deu-se-Ihe também maior rigor interpretativo com estabelecer-se uma distinção fundamental entre EVOLUÇÃO propriamente dita e o empréstimo. Abrange este segundo fenômeno o conjunto de mudanças que uma língua sofre em contacto com outras. (MATTOSO CÂMARA JR., 1974 [1942], p. 192) 
Percebe-se, nessas obras, produzidas entre 1908 e 1959, a preferência pelo uso da palavra empréstimo, embora haja, implicitamente, a ideia de estrangeirismo, com a menção, no $2^{\circ}$ excerto, a latinismos, grecismos, hispanismos, italianismos e galicismos. Entretanto, essa referência dada por Said Ali parece estar mais relacionada a uma preocupação com a informação sobre a origem das palavras que com o estatuto delas na língua receptora.

Quanto às ocorrências do primeiro grupo de obras do corpus, as seguintes ocorrências merecem destaque:

(5) [...] chegamos aos empréstimos, que nada mais são do que adoção de traços lingüísticos diversos do sistema tradicional da língua importadora. (BORBA, 1975 [1965], p. 277)

(6) Do ponto de vista formal podemos reconhecer três tipos de estrangeirismos: a) Decalque: Nesse caso procedeu-se a uma versão literal do lexema modelo na língua originária. (BIDERMAN, 2001 [1978], p. 208)

(7) Em outras etapas da história da nossa língua registram-se muitos empréstimos de origem francesa. Hoje os anglicismos prevalecem sobre todos os outros tipos de estrangeirismos." (BIDERMAN, 2001 [1978], p. 208)

(8) O neologismo pode decorrer da importação de um termo que pertença a outro sistema lingüístico. Propomos, pois, uma ampliação na formalização dos processos de formação neológica - que são apresentados comumente como o da derivação, o da composição e o do empréstimo [...]. (BARBOSA, 1979, p. 166)

(9) Empréstimo: palavra que foi tomada emprestada de uma outra língua por não existir termo correspondente no idioma que acolheu o empréstimo. Esse empréstimo, com freqüência, incorpora-se ao vocabulário vernáculo. (BIDERMAN, 1984, p. 138)
(10) [...] Ocorre lexicalização na evolução histórica de uma língua: 1) quando um empréstimo estrangeiro passa a fazer parte do léxico da língua (ex.: coquetel, futebol, butique) [...]. (BIDERMAN, 1984, p. 140)

(11) Utilizaremos estrangeirismo para designar termo ou expressão sentidos como externos à língua portuguesa. $\mathrm{O}$ estrangeirismo que está se instalando é um verdadeiro neologismo e somente se tornará empréstimo quando não mais for sentido como estranho ao sistema da língua [...]. (ALVES, 1988, p. 3)

(12) Já o neologismo por adoção, ou empréstimo, é de uso mais comum [...]" (CARVALHO, 2010)

(13) A adoção linguística compreende diversas etapas até a completa identificação da palavra com a língua que a acolheu. [...] Somente será empréstimo posteriormente, quando adotado verdadeiramente pela integração à forma da língua e pelo uso corrente entre os falantes. [...] Se o termo importado permanece na grafia original, mesmo sendo muito usado, será um xenismo. (CARVALHO, 2010)

(14) Numa primeira etapa, o elemento estrangeiro, empregado em outro sistema linguístico, é sentido como externo ao vernáculo dessa língua. É então denominado estrangeirismo, ou seja, ainda não faz parte do acervo lexical do idioma. (ALVES, 2001 [1990], p. 72)

(15) [...] dizemos que a adaptação de um vocábulo de uma língua $B$ ao sistema lingüístico de uma língua $A$ é um caso de empréstimo, enquanto que 0 estrangeirismo consiste na adoção do vocábulo da língua B em sua forma original. (XATARA, 1992, p. 99)

(16) [...] e mais adiante: "Deve ficar bem clara a distinção entre empréstimo e estrangeirismo (...) o empréstimo é o estrangeirismo adaptado de várias formas, (p. 47)". Por exemplo: - banane no francês representa um empréstimo da forma 'banana' 
portuguesa; - offset no francês representa um estrangeirismo inglês. (XATARA, 1992, p. 100)

Nessas ocorrências, de artigos e obras publicados entre 1978 e 1992, há uma variação no emprego de empréstimo e estrangeirismo, usados, em alguns casos, como sinônimos. Os autores que os diferenciam, adotam como critérios a adaptação gráfica e/ou fonética à língua importadora (ocorrências 13, 15 e 16), ou o sentimento de pertencimento ao sistema linguístico pelo falante nativo (ocorrências 11 e 14). Aparece, ainda, o termo xenismo, emprestado do francês.

Do terceiro grupo de obras, são exemplos:

(17) Ela pode constituir-se de elementos provenientes de outros sistemas linguísticos - traduzidos ou não (decalques e estrangeirismos ou empréstimos) [...]". (PILLA, 2002, p. 13)

(18) Neste trabalho, optámos por utilizar apenas a designação estrangeirismo (ou palavra estrangeira), uma vez que é aquela que nos parece mais transparente e intuitiva, não obstante haver uma certa carga depreciativa associada à mesma. (FREITAS; RAMILO; SOALHEIRO, 2003, s.p.)

(19) Estrangeirismos e empréstimos são transcritos de diferentes formas [...]. Deroy classifica as unidades lexicais de origem estrangeira em estrangeirismos ou peregrinismos e empréstimos [...]. Os primeiros ainda são percebidos como externos à língua receptora, similares a uma citação; já os segundos perderam, para os falantes, o caráter estrangeiro. (ALVES, 2019, s.p.)

Nestas ocorrências, observa-se variação próxima à verificada nos excertos do grupo 1 , reproduzidos anteriormente, com a diferença de que surge o termo peregrinismo, atribuído ao autor Deroy, e o que parece ser uma predileção pelo termo estrangeirismo por alguns pesquisadores portugueses.

\section{Considerações finais}

Por meio dessa análise inicial, foi possível verificar que, num primeiro momento, filólogos e gramáticos empregavam prioritariamente 0 termo empréstimo; com o surgimento de uma área da Linguística especializada nos estudos da Neologia e nos processos de empréstimo lexical, o crescimento da produção científica parece ter levado a uma popularização do termo, que passou a concorrer com estrangeirismo, mesmo existindo uma diferenciação entre eles. Como foi mostrado por meio do estudo das ocorrências encontradas no corpus desta pesquisa, essa distinção entre os termos empréstimo e estrangeirismo nem sempre é explicada de maneira clara e precisa pelos autores em seus trabalhos, o que pode ter dado início à imprecisão terminológica aqui analisada.

No que diz respeito aos significados das duas unidades terminológicas, pode-se afirmar que ambas estão relacionadas ao fenômeno linguístico da neologia por empréstimo. Uma distinção completa deveria contemplar os critérios apresentados por Alves (1988; 2001 [1990]; 2018), Biderman (1984), Carvalho (2010 [1989]) e Xatara (1992): estrangeirismo designa a palavra que ainda é percebida pelos falantes como não pertencente ao sistema linguístico, pois não faz parte do seu acervo lexical, e geralmente mantém sua forma sonora e gráfica original, funcionando como uma citação. Nessa etapa, em que está se instalando, ela é um verdadeiro neologismo, está em processo de integração, e somente se tornará empréstimo quando não for mais sentida como estranha ao sistema da língua, ou seja, quando for lexicalizada, integrada ao idioma, e tiver uso corrente entre os falantes.

Dessa forma, o termo empréstimo mostra-se polissêmico, designando o processo, neologia por empréstimo, e o resultado, empréstimo, estatuto final da palavra que entra numa língua por meio de sua importação de um outro sistema linguístico.

Não se pode deixar de mencionar a questão ideológica que envolve 0 emprego de estrangeirismos, sustentando argumentos de 
discursos conservadores em favor do purismo linguístico e do combate aos empréstimos lexicais, que de tempos em tempos ganham força na sociedade brasileira. A presença do sema [que é estrangeiro], que pode ser interpretado como "que não é nosso", "que não é nacional", pode levar ao sentido, em discurso, de perda de identidade, diferentemente do que ocorre com o termo empréstimo, que não apresenta esse traço de significação. Percebe-se, assim, que a distinção entre os termos apresentada acima - emprego + estrangeirismo (como algo temporário, inicial) e inclusão no sistema + empréstimo (como resultado do processo) - além de diminuir a imprecisão terminológica, pode contribuir para enfraquecer os recorrentes argumentos puristas.

Para finalizar, lembra-se que deve ser considerada, ainda, a influência de obras de referência internacionais e os sucessivos processos de tradução a que são submetidas a cada citação, o que também pode ocasionar a variação terminológica em língua portuguesa.

\section{Referências}

ALVES, leda Maria. Metalinguagem e empréstimo na mensagem publicitária. In: Alfa. São Paulo: UNESP, 1984a, n. 28, p. 97-100.

ALVES, leda Maria. A integração dos neologismos por empréstimo ao léxico português. In: Alfa. São Paulo: UNESP, 1984b, n. 28 (supl.), p. 119-126.

ALVES, leda Maria. Empréstimos lexicais na imprensa política brasileira. In: Alfa. São Paulo: UNESP, 1988, n. 32, p. 1-14.

ALVES, leda Maria. Neologia e níveis de análise linguística. In: OLIVEIRA, Ana Maria Pinto Pires de; ISQUERDO, Aparecida Negri; ALVES, leda Maria. As ciências do léxico: lexicologia, lexicografia, terminologia. São Paulo: Humanitas, 2001 , v. 3, p. $77-92$.

ALVES, leda Maria. Neologismo: criação lexical. $2^{\text {a }}$ ed. São Paulo: Ática, 2002 [1990].

ALVES, leda Maria. Integração de estrangeirismos à língua portuguesa. In: I Simpósio Mundial de Estudos da Língua Portuguesa (SIMELP). São Paulo: FFLCH - USP, 2008, simpósio 24. Disponível em: <http://simelp.fflch.usp.br/slp24>. Consulta em: 15 jul.2019.
ALVES, leda Maria. Integração de estrangeirismos à língua portuguesa. In: TEIXEIRA; VII Simpósio Mundial de Estudos da Língua Portuguesa (SIMELP). Simpósio "A Neologia e o Ensino da Língua Portuguesa". Porto de Galinhas (Pernambuco), 2019 (ago). Disponível em: $<$ http://simelp.fflch.usp.br/sites/simelp.fflch.usp.br/fi les/inline-files/S2402.pdf>. Consulta em: 25 jul.2019.

BARBOSA, Maria Aparecida. Aspectos semânticos da produtividade léxica. In: Língua e literatura, 1979, v. 8 , p. $165-183$.

BARBOSA; JANSSEN. Dicionário de Estrangeirismos. In: Portal da Língua Portuguesa. Lisboa: ILTEC, 2007-2011, on-line. Disponível em: <http://www.portaldalinguaportuguesa.org/?action $=$ estrangeirismos\&page $=$ present $>$. Consulta em: 15 jul.2019.

BENVENISTE, Émile. Problemas de Linguística Geral. Trad. Maria da Glória Novak e Maria Luisa Neri. 4a ed. Campinas (São Paulo): Editora da Unicamp; Pontes, 1995.

BIDERMAN, M. T. C. A Ciência da lexicografia. In: Alfa. São Paulo, 1984, n. 28 (supl.), p 1-26.

BIDERMAN, Maria Tereza C. Glossário. In: Alfa. São Paulo: UNESP, 1984, n. 28 (supl.), p 135-144.

BIDERMAN, Maria Tereza C. Teoria Linguística: teoria linguística e computacional. $2^{\underline{a}}$ ed. São Paulo: Martins Fontes, 2001 [1978].

BORBA, Francisco da Silva. Introdução aos estudos linguísticos. 4a ed. São Paulo: Companhia Editora Nacional, 1975 [1965], 316p.

BOTTA, M. G. O vocabulário político-ideológico da Gazeta de Lisboa no século XVIII: estudo do léxico em perspectiva discursiva. Tese de Doutorado. Apresentada ao Programa de PósGraduação em Linguística e Língua Portuguesa da Faculdade de Ciências e Letras de Araraquara - FCL/CAr (UNESP) e à École Doctorale 268 Langage et langues: description, théorisation, transmission da Université Sorbonne Nouvelle Paris III. Araraquara (SP): UNESP, 2011. Disponível em: <https://repositorio.unesp.br/handle/11449/103571 >. Consulta em: 27 jul.2019.

BOULANGER, J. C. Néologie et terminologie. In: Néologie en Marche. Serie B: Langues de spécialités. Montréal (Canada), 1979, n. 4, p. 5127.

CÂMARA JR., Joaquim Mattoso. Princípios de Linguística Geral: como introdução aos estudos superiores da língua portuguesa. $4^{\mathrm{a}}$ ed. revista e aumentada. $7^{\underline{a}}$ reimpressão. Rio de Janeiro: Livraria Acadêmica, 1974 [1942], 333p. 
CARVALHO, Nelly Medeiros de. Empréstimos Lingüísticos. Coleção Princípios. São Paulo: Ática, 1989.

CARVALHO, Nelly Medeiros de. Caminhos do neologismo no Brasil. In: ALVES, I. M. Neologia e neologismos em diferentes perspectivas. São Paulo: Paulistana, 2010, p. 277-291.

CORREIA, Margarita; ANTUNES, Mafalda. A classificação de neologismos: objetivos e problemas. In: Cabré, M.T.; Domènech, O. et alii. (eds.). Actes del Congrés Internacional de Neología en les llengües Romàniques (CINEO). Barcelona, IULAUPF, 2010, p. 749-758.

CORREIA, Margarita; MINEIRO, Ana. Neologia de importação no português europeu: desafios e medidas a tomar. In: Actas do XX Encontro Nacional da Associação Portuguesa de Linguística (APL). Lisboa, 2004, p. 33-54. Disponível em: $<$ http://www.iltec.pt/pt/handler.php?action=artigos\& book=111>. Consulta em: 15 jul.2019.

ELUERD, Roland. La lexicologie. Que sais-je? Paris: Presses Universitaires de France, 2000, 128 p.

FREITAS, Tiago; RAMILO, Maria Celeste; SOALHEIRO, Elisabete. O processo de integração dos estrangeirismos no português europeu. In: Mendes; Freitas (orgs.) Actas do XVIII Encontro Nacional da Associação Portuguesa de Linguística. $2003 . \quad$ Disponível em: <http://www.iltec.pt/pdf/wpapers/2003-redipestrangeirismos.pdf>. Consulta em: 17 jul.2019.

GUILBERT, Louis. Théorie du néologisme. In: Cahiers de l'Association internationale des études françaises. 1973, $\mathrm{n}^{\circ} 25$, p. 9-29.

GUILBERT, Louis. La créativité lexicale. Paris, Larousse, 1975.

HUMBLEY, John. Emprunts, vrais et faux, dans le Petit Robert. In: La journée des dictionnaires. Cergy-Pontoise (France), 2007 (mar.), p. 221-238.

LYONS, John. Semántica. Coleção Métodos. Barcarena (Portugal): Editorial Presença, 1977, v. 1.

MOIRAND, Sophie. Le dialogisme, entre problématiques énonciatives et théories discursives. In: Cahiers de praxématique. Aspects du dialogisme. Montpellier: Presses universitaires de la Méditerranée, 2004, n 43, p. 189-220.

MEL'ČUK, Igor et al. Dictionnaire explicatif et combinatoire $d u$ français contemporain.
Recherches lexico-sémantiques I. Montréal (Canada): Les Presses de l'Université de Montréal, 1984, $172 \mathrm{p}$.

PILLA, Éda Heloisa. Os neologismos do português e a face social da língua. Age, 2002.

POTTIER, Bernard. Du très général au trop particulier. In: Travaux de linguistique et de littérature (TraLiLi). Strasbourg (França): Université de Strasbourg; Klincksieck, 1963, v. 1.

PRUVOST, Jean.; SABLAYROLLES, Jean-François. Les Néologismes. Que sais-je? 2 ${ }^{\mathrm{a}}$ ed. Paris: 2012 [2003], $125 \mathrm{p}$.

SABLAYROLLES, Jean-François. Fondements théoriques des difficultés pratiques du traitement des néologismes. In: Revue française de linguistique appliquée. 2002, n. 1, v. 7, p. 97-111. Disponível em: <https://www.cairn.inforevuefrancaise-de-linguistique-appliquee-2002-1-page97.htm>. Consulta em: 20 jul.2019.

SABLAYROLLES, Jean-François. Néologie et classes d'objet. In: Neologica: revue internationale de la néologie. Paris: Garnier, 2009, p. 25-36. Disponível em: <https://halshs.archivesouvertes.fr/halshs-00608879/document>. Consulta em: 17 jul.2019.

SABLAYROLLES, Jean-François; JACQUET-PFAU, Christine; HUMBLEY, John. Emprunts, créations sous influence et équivalents. In: Actes des $8^{e}$ Journées scientifiques du réseau LTT de l'AUF (out/2009) - Passeurs de mots, passeurs d'espoir: lexicologie, terminologie et traduction face au défi de la diversité. Lisboa (Portugal): Édition des archives contemporaines, 2011 [2009], p. 325-339.

SAID ALI, Manuel. Dificuldades da língua portuguesa: estudos e observações. Coleção Antônio de Morais Silva. $7^{\underline{a}}$ ed. Rio de Janeiro: ABL; Biblioteca Nacional, 2008 [1908], v. 7, 260 p. Disponível em: $<$ http://www.academia.org.br/abl/media/Dificuldade s\%20da\%20Lingua\%20Portuguesa\%20\%20CAMS\%20-\%20PARA\%20INTERNET.pdf>.

SILVEIRA BUENO, Francisco da. Estudos de Filologia Portuguesa. 6aㅗ ed. São Paulo: Saraiva, 1967 [1959], 241p.

TOGEBY, Knud. Structure immanente de la langue française. Paris: Larousse, 1965, 208 p.

XATARA RODRIGUES, Cláudia Maria. Empréstimos, estrangeirismos e suas medidas. In: Alfa. São Paulo: UNESP, 1992, n. 36, p. 99-109.

\section{COMO CITAR ESSE ARTIGO}

BOTTA, Mariana Giacomini. Breve estudo sobre os usos dos termos empréstimo e estrangeirismo na tradição linguística em língua portuguesa. Signo, Santa Cruz do Sul, v. 45, n. 82, jan. 2020. ISSN 1982-2014. Disponível em: <https://online.unisc.br/seer/index.php/signo/article/view/14356>.

em: doi:https://doi.org/10.17058/signo.v45i82.14356. 